$5-1-2012$

\title{
Ordinal Regression Analysis: Using Generalized Ordinal Logistic Regression Models to Estimate Educational Data
}

Xing Liu

Eastern Connecticut State University, liux@easternct.edu

Hari Koirala

Eastern Connecticut State University

Follow this and additional works at: http://digitalcommons.wayne.edu/jmasm

Part of the Applied Statistics Commons, Social and Behavioral Sciences Commons, and the Statistical Theory Commons

\section{Recommended Citation}

Liu, Xing and Koirala, Hari (2012) "Ordinal Regression Analysis: Using Generalized Ordinal Logistic Regression Models to Estimate Educational Data," Journal of Modern Applied Statistical Methods: Vol. 11 : Iss. 1 , Article 21.

DOI: $10.22237 /$ jmasm/1335846000

Available at: http://digitalcommons.wayne.edu/jmasm/vol11/iss1/21 


\title{
Ordinal Regression Analysis: Using Generalized Ordinal Logistic Regression Models to Estimate Educational Data
}

\author{
Xing Liu \\ Hari Koirala \\ Eastern Connecticut State University, \\ Willimantic, CT
}

The proportional odds (PO) assumption for ordinal regression analysis is often violated because it is strongly affected by sample size and the number of covariate patterns. To address this issue, the partial proportional odds (PPO) model and the generalized ordinal logit model were developed. However, these models are not typically used in research. One likely reason for this is the restriction of current statistical software packages: SPSS cannot perform the generalized ordinal logit model analysis and SAS requires data restructuring. This article illustrates the use of generalized ordinal logistic regression models to predict mathematics proficiency levels using Stata and compares the results from fitting PO models and generalized ordinal logistic regression models.

Key words: Generalized ordinal logistic regression models, proportional odds models, partial proportional odds model, ordinal regression analysis, mathematics proficiency, stata, comparison.

\section{Introduction}

Ordinal data in education are substantive. Perhaps the most well-known model for estimating an ordinal outcome variable is the proportional odds (PO) model (Agresti, 1996, 2002, 2007; Anath \& Kleinbaum, 1997; Armstrong \& Sloan, 1989; Hardin \& Hilbe, 2007; Long, 1997; Long \& Freese, 2006; McCullagh, 1980; McCullagh \& Nelder, 1989; O'Connell, 2000, 2006; Powers \& Xie, 2000). Current general-purpose statistical software packages, such as SAS, SPSS and Stata, use this model as the default for ordinal regression analysis. The PO model is used to estimate the cumulative probability of being at or below a particular level of a response variable, or being beyond a particular level, which is the complementary direction. In this model, the effect of each predictor is assumed to be the

Xing Liu is an Associate Professor of Research and Assessment in the Education Department. Email him at: liux@easternct.edu. Hari Koirala is a Professor in the Education Department. Emailhim at:koiralah@easternct.edu. same across the categories of the ordinal dependent variable. This means that for each predictor, the effect on the odds of being at or below any category remains the same within the model. This restriction is referred to as the proportional odds, or the parallel lines, assumption.

The assumption of proportional odds is often violated, however, because it is strongly affected by sample size and the number of covariate patterns - for example, including continuous covariates or interactions as the predictors (Allison, 1999; Brant, 1990; O'Connell, 2006). It is misleading and invalid to interpret results if this assumption is not tenable. It has been suggested that the separate underlying binary logistic regression models are fitted and then are compared with the original PO model (Allison, 1999; Bender \& Grouven, 1998; Brant, 1990; Clogg \& Shihadeh, 1994; Long, 1997; O'Connell, 2000, 2006). Although this strategy would help researchers identify the reason why the overall PO assumption is violated, it is not clear how a well-fitting parsimonious model with a violated PO assumption is developed and interpreted.

To address this issue, the partial proportional odds (PPO) model (Peterson \& 


\section{XING LIU \& HARI KOIRALA}

Harrell, 1990) and the generalized ordinal logit model (Fu, 1998; Williams, 2006) were developed. The PPO model allows for interactions between a predictor variable that violates the PO assumption and different categories of the ordinal outcome variable. The analysis of a PPO model using SAS GENMOD procedure requires a restructured data set, which includes a new binary variable indicating whether an individual is at or beyond a particular level (O'Connell, 2006; Stokes, Davis \& Koch, 2000).

The generalized ordinal logit model developed by $\mathrm{Fu}$ (1998) and William (2006) relaxes the PO assumption by allowing the effect of each explanatory variable to vary across different cut points of the ordinal outcome variable without data restructuring. In addition, this model estimates parameters differently from the PPO model using SAS. Williams' gologit2 program (2006) for Stata is a more powerful extension of Fu's gologit (1998); it can estimate the generalized ordered logit model, the PPO model, the PO model and the logistic regression model within one program.

In educational research, the PO model is widely used. However, the use of the generalized ordinal logit model appears to be overlooked even in cases where the PO assumption is violated. One likely reason for this is the restriction of current statistical software packages: SPSS cannot perform the generalized ordinal logit model analysis and SAS requires data restructuring prior to data analysis, therefore, it is important to help educational researchers better understand this model and utilize it in practice.

The purpose of this study is to illustrate the use of generalized ordinal logistic regression models to predict mathematics proficiency levels using Stata and to compare the results of fitting PO and the generalized ordinal logistic regression models. This article is an extension of previous research focusing on the PO model (Liu, 2009), and the Continuation Ratio model with Stata (Liu, O'Connell, \& Koirala, 2011). Ordinal regression analyses are based on data from the 2002 Educational Longitudinal Study (ELS) in which the ordinal outcome of students' mathematics proficiency was forecast from a set of predictors, such as, using computers for fun, school work and to learn on their own.

Theoretical Framework

General Logistic Regression Model and the Proportional Odds Model

The binary logistic regression model estimates the odds of success or experiencing an event for the dichotomous response variable given a set of predictors. The logistic regression model can be defined as (Allison, 1999; Menard, 1995):

$$
\begin{aligned}
\ln \left(\mathrm{Y}^{\prime}\right) & =\operatorname{logit}[\pi(\underline{\mathrm{x}})] \\
& =\ln \left(\frac{\pi(\underline{\mathrm{x}})}{1-\pi(\underline{\mathrm{x}})}\right) \\
& =\alpha+\beta_{1} \mathrm{X}_{1}+\beta_{2} \mathrm{X}_{2}+\ldots+\beta_{\mathrm{p}} \mathrm{X}_{\mathrm{p}}
\end{aligned}
$$

In an ordinal logistic regression model, the outcome variable has more than two levels. It estimates the probability being at or below a specific outcome level given a collection of explanatory variables. The ordinal logistic regression model can be expressed in the logit form (Liu, 2009; Long, 1997; Long \& Freese, 2006) as follows:

$$
\begin{aligned}
\ln \left(\mathrm{Y}_{\mathrm{j}}^{\prime}\right) & =\operatorname{logit}[\pi(\mathrm{x})] \\
& =\ln \left(\frac{\pi(\mathrm{x})}{1-\pi(\mathrm{x})}\right) \\
& =\alpha_{\mathrm{j}}+\left(-\beta_{1} \mathrm{X}_{1}-\beta_{2} \mathrm{X}_{2}-\ldots-\beta_{\mathrm{p}} \mathrm{X}_{\mathrm{p}}\right)
\end{aligned}
$$

where $\pi_{\mathrm{j}}(\underline{\mathrm{x}})=\pi\left(\mathrm{Y} \leq \mathrm{j} \mid \mathrm{x}_{1}, \mathrm{x}_{2}, \ldots, \mathrm{x}_{\mathrm{p}}\right)$ is the probability of being at or below category $\mathrm{j}$, given a set of predictors, $\mathrm{j}=1,2, \ldots, \mathrm{J}-1, \alpha_{\mathrm{j}}$ are the cut points and $\beta_{1}, \beta_{2}, \ldots, \beta_{\mathrm{p}}$ are logit coefficients. When there are $\mathrm{j}$ categories, the PO model estimates J-1 cut points. This PO model assumes that the logit coefficient of any predictor is independent of categories, i.e., the coefficients for the underlying binary models are the same across all cutpoints. The equal logit slope or the proportional odds assumption can be assessed by the Brant test (Brant, 1990), which estimates logit coefficients for underlying binary logistic regressions, and provides the chi-square test 


\section{GENERALIZED ORDINAL LOGISTIC REGRESSION MODELS}

statistics for each predictor and the overall model in Stata.

To estimate the ln (odds) of being at or below the $\mathrm{j}^{\text {th }}$ category, the PO model can be rewritten as the following form:

$$
\begin{aligned}
\operatorname{logit} & {\left[\pi\left(Y \leq j \mid x 1, x 2, \ldots, x_{p}\right)\right] } \\
& =\ln \left(\frac{\pi\left(Y \leq j \mid x_{1}, x_{2}, \ldots, x_{p}\right)}{\pi\left(Y>j \mid x_{1}, x_{2}, \ldots, x_{p}\right)}\right) \\
& =\alpha_{j}+\left(-\beta_{1} X_{1}-\beta_{2} X_{2}-\ldots-\beta_{p} X_{p}\right) .
\end{aligned}
$$

Thus, this model predicts cumulative logits across $\mathrm{J}-1$ response categories. The cumulative logits can then be used to calculate the estimated cumulative odds and the cumulative probabilities being at or below the $\mathrm{j}^{\text {th }}$ category.

Different software packages may estimate parameters differently and the ordinal logistic regression model can be expressed in different forms (Liu, 2009). For example, Stata follows the above form with a negative sign before the logit coefficients. SAS, however, uses a different form when estimating the cumulative odds of being at or below a particular category using the ascending option.

The Generalized Ordinal Logistic Regression Model

The generalized ordinal logistic regression model extends the $\mathrm{PO}$ model by relaxing the $\mathrm{PO}$ assumption. In this model, if the assumption is violated by a certain predictor, then its effect can be estimated freely across different categories of the dependent variable. The model is expressed as:

$$
\begin{aligned}
\ln \left(Y_{j}{ }^{\prime}\right) & =\ln \left(\frac{\pi_{j}(\underline{x})}{1-\pi_{j}(\underline{x})}\right) \\
& =\alpha_{j}+\left(\beta_{1 j} X_{1}+\beta_{2 j} X_{2}+\ldots+\beta_{p j} X_{p}\right) .
\end{aligned}
$$

The above form can also be expressed as proposed by $\mathrm{Fu}$ (1998) and Williams (2006):

$$
\begin{aligned}
\operatorname{logit} & {\left[\pi\left(Y>j \mid x 1, x 2, \ldots, x_{p}\right)\right] } \\
= & \ln \left(\frac{\pi\left(Y>j \mid x_{1}, x_{2}, \ldots, x_{p}\right)}{\pi\left(Y \leq j \mid x_{1}, x_{2}, \ldots, x_{p}\right)}\right) \\
& =\alpha_{j}+\left(\beta_{1 j} X_{1}+\beta_{2 j} X_{2}+\ldots+\beta_{p j} X_{p}\right),
\end{aligned}
$$

where, in both equations, $\alpha_{j}$ are the intercepts or cutpoints, and $\beta_{1 \mathrm{j}}, \beta_{2 \mathrm{j}}, \ldots, \beta_{\mathrm{pj}}$ are logit coefficients. This model estimates the odds of being beyond a certain category relative to being at or below that category. A positive logit coefficient generally indicates that an individual is more likely to be in a higher category as opposed to a lower category of the outcome variable. To estimate the odds of being at or below a particular category, however, the signs before both the intercepts and logit coefficients in equation (5) must be reversed.

In this expression, all of the effects of the explanatory variables are allowed to vary across each of the cutpoints. If some of these effects are found to be stable, they can be constrained to be equal as in the PO model; thus, generalized ordinal logistic regression model refers to the case where at least one of the coefficients for a predictor varies across categories. Compared to SAS, neither data restructuring nor interactions between categories and predictor variables with non-proportional odds are required by Stata - this makes data analysis of the generalized ordinal logit model much easier.

Sample

\section{Methodology}

The data used in this study are from the Educational Longitudinal Study of 2002 (ELS: 2002). The ELS 2002 study, conducted by the National Center for Educational Statistics (NCES), was designed to provide longitudinal data regarding high school students' achievement, attitude and experiences, and their postsecondary school education and the labor market. In the 2002 base year of the study a cohort of more than 15,000 high school sophomores from a national sample of 752 public and private high schools participated in 


\section{XING LIU \& HARI KOIRALA}

the study by taking cognitive tests and responding to surveys.

The outcome variable was students' mathematics proficiency levels in high school, which was an ordinal variable with five levels (1 = students can do simple arithmetical operations on whole numbers; 2 = students can do simple operations with decimals, fractions, powers, and root; $3=$ students can do simple problem solving; $4=$ students can understand intermediate-level mathematical concepts and/or find multi-step solutions to word problems; and $5=$ students can solve complex multiple-step word problems and/or understand advanced mathematical material) (Ingels, Pratt, Roger, Siegel, \& Stutts, 2004, 2005). These five proficiency domains were hierarchically structured: mastery of higher proficiency level indicated mastery of all previous levels. Those students who failed to pass through level 1 were assigned to level 0 . Table 1 provides the categories and frequencies of all mathematics proficiency levels.
Data Analysis.

After the PO model was fitted with a single explanatory variable using the Stata ologit command the full-model was then fitted with all three explanatory variables. The brant test command, one of the Stata SPost (Long \& Freese, 2006) routines for the analysis of postestimations, was used to examine the PO assumption and identify predictors that violated the assumption. Stata gologit (Fu, 1998) and gologit2 (Williams, 2006) commands were then used to fit the generalized ordinal regression models and the results from both PO models and the generalized ordinal regression models were compared.

\section{Results}

Proportional Odds Model with a Single Explanatory Variable

A PO model with a single predictor, using computers for fun, was fitted first using the Stata ologit command with the logit function as default. Table 2 provides the results for the single-predictor PO model.

Table 1: Proficiency Categories and Frequencies (Proportions) for the Study Sample, ELS $2002(\mathrm{~N}=15,976)$

\begin{tabular}{|c|c|c|}
\hline $\begin{array}{l}\text { Proficiency } \\
\text { Category }\end{array}$ & Description & $\begin{array}{l}\text { Frequency and } \\
\text { Percent of Total Sample }\end{array}$ \\
\hline 0 & Did not pass level 1 & $\begin{array}{c}842 \\
(5.27 \%)\end{array}$ \\
\hline 1 & Can do simple arithmetical operations on whole numbers & $\begin{array}{c}3,882 \\
(24.30 \%)\end{array}$ \\
\hline 2 & $\begin{array}{l}\text { Can do simple operations with decimals, fractions, powers, } \\
\text { and root }\end{array}$ & $\begin{array}{c}3,422 \\
(21.42 \%)\end{array}$ \\
\hline 3 & Can do simple problem solving & $\begin{array}{c}4,521 \\
(28.30 \%)\end{array}$ \\
\hline 4 & $\begin{array}{l}\text { Can understand intermediate-level mathematical concepts } \\
\text { and/or find multi-step solutions to word problems }\end{array}$ & $\begin{array}{c}3,196 \\
(20.01 \%)\end{array}$ \\
\hline 5 & $\begin{array}{c}\text { Can solve complex multiple-step word problems and/or } \\
\text { understand advanced mathematical material }\end{array}$ & $\begin{array}{c}113 \\
(0.71 \%)\end{array}$ \\
\hline
\end{tabular}




\section{GENERALIZED ORDINAL LOGISTIC REGRESSION MODELS}

The log likelihood ratio Chi-Square test with 1 degree of freedom, LR $\chi_{(1)}^{2}=992.52, p<$ 0.001 , indicated that the logit regression coefficient of the predictor (using computer for fun) was statistically different from 0 , therefore, the model with one predictor provided a better fit than the null model with no independent variables. The Pseudo $R^{2}=0.023$, which is the likelihood ratio $R_{L}^{2}$, suggested that the relationship between the response variable, mathematics proficiency, and the predictor, using computer for fun, was small.

The estimated logit regression coefficient, $\beta=0.384, \mathrm{z}=31.28, \mathrm{p}<0.001$, indicated that the predictor variable, using computers for fun, had a significant effect on mathematics proficiency. Substituting the value of the coefficient into formula (3), logit $[\pi(Y \leq j$ $\left.\left.\mid \mathrm{X}_{1}\right)\right]=\alpha_{\mathrm{j}}+\left(-\beta_{1} \mathrm{X}_{1}\right)$, logit $[\pi(\mathrm{Y} \leq \mathrm{j} \mid$ fun $)]=$ $\alpha_{j}-0.384$ (fun). OR $=\mathrm{e}^{(-0.384)}=0.681$, indicated that the odds of being at or below a particular proficiency level relative to beyond that level decreased by a factor of 0.681 with one unit increase in the frequency of using computers for fun. In other words, a higher frequency of using computers for fun was related to the likelihood of being in a higher proficiency level. To estimate the probability of being beyond a category of mathematics proficiency, which is the complement of the probability of being at or below a category, it is only necessary to exponentiate 0.384 ; this results in $\mathrm{OR}=1.468$, indicating that the odds of being beyond a proficiency level was 1.468 time greater with one unit increase in the frequency of using computers for fun.

Full Proportional Odds Model with Three Predictor Variables

Next, the full PO model with all three predictor variables was fitted. Table 2 provides the results of the full model. The log likelihood ratio Chi-Square test, LR $\chi_{(3)}^{2}=1391.45, \mathrm{p}<$ 0.001 , indicated that the full model with three predictor provided a better fit than the null model with no independent variables. The likelihood ratio $R_{L}^{2}=0.032$ was larger than that of the single-variable model, but was still small. Compared with the single-variable model (3.020), the AIC statistic indicated that the fullmodel fitted the data slightly better (2.992).
The logit effects of all three predictors on mathematics proficiency were significant. Similar to the single variable PO model, the estimated logit regression coefficient for using computers for fun (fun), $\beta=0.314, \mathrm{z}=22.44, \mathrm{p}$ $<0.001$; the logit coefficient for using computers for school work (schoolwk), $\beta=$ $0.307, \mathrm{z}=19.815, \mathrm{p}<0.001$; and finally, for using computers to learn on their own (learn), $\beta$ $=-0.072, \mathrm{z}=-5.295, \mathrm{p}<0.001$. The predictors, using computers for fun and using computers for school work, were positively associated with the odds of being beyond a proficiency level. In terms of odds ratio (OR), the odds of being beyond a proficiency level were 1.369 times greater with one unit increase in the frequency of using computers for fun, and 1.360 times greater with one unit increase in the frequency of using computers for school work. For every one unit increase in using computers to learn on their own, however, the odds of being beyond a particular category decreased by a factor of $0.931(\mathrm{OR}=0.931)$.

The full model also estimated five cutpoints, which were used to differentiate adjacent categories of the mathematics proficiency. $\alpha_{1}=-1.022$, which was the cutpoint for the cumulative logit model for $Y>0 ; \alpha_{2}$ was the cutpoint for the cumulative logit model for $Y>1$; the final $\alpha_{5}$ was used as the cutpoint for the logit model when $Y>4$.

Brant Test of the Proportional Odds Assumption

The Brant test of the PO assumption was examined using the brant command of the Stata SPost (Long \& Freese, 2006) routines. Stata Brant test provided results of a series of separate binary logistic regression across different category comparisons, univariate Brant test results for each predictor and the omnibus test for the overall model. Table 3 shows five $(j-1)$ associated binary logistic regression models for the full PO model, where each split compares $\mathrm{Y}$ $>$ cat. $j$ to $Y \leq$ cat. $j$ because data were dichotomized according to probability comparisons. Examining the logit coefficient of all three variables across five logistic regression models, it is evident that the effect of using computers for fun was similar across these models. The effect of using computers for 
school work was similar across the first three models but it increased from model 3 to 5 . The logit coefficient in model 5 was almost double that observed in model 1. The effect of using computers to learn on their own was close among the first four logistic regression models, however, the direction of this effect changed in model 5. Visual examination provided only preliminary results of whether the parallel effects assumption was tenable.
To test the PO assumptions, the Brant test provided the results for the overall model and each predictor. Table 4 presents $\chi^{2}$ tests and $\mathrm{p}$ values for the full PO model and separate variables. The omnibus Brant test for the full model, $\chi_{12}^{2}=29.59, p=0.003$, indicates that the proportional odds assumption for the full model was violated. To identify which predictor variables violated the assumption, separate Brant tests were examined for each predictor variable.

Table 2: Results of the Single-Variable PO Model and the Full PO Model

\begin{tabular}{|c|c|c|c|c|}
\hline \multirow[b]{2}{*}{ Variable } & \multicolumn{2}{|c|}{ Single-Variable Model } & \multicolumn{2}{|c|}{ Full Model } \\
\hline & $\mathrm{b}(\mathrm{se}(\mathrm{b}))$ & OR & $\mathrm{b}(\mathrm{se}(\mathrm{b}))$ & OR \\
\hline$\alpha_{1}$ & -1.488 & & -1.022 & \\
\hline$\alpha_{2}$ & .627 & & 1.20 & \\
\hline$\alpha_{3}$ & 1.571 & & 2.082 & \\
\hline$\alpha_{4}$ & 2.900 & & 3.437 & \\
\hline$\alpha_{5}$ & 6.475 & & 7.033 & \\
\hline fun & $.384 * *$ & 1.468 & $.314 * *$ & 1.369 \\
\hline schoolwk & & & $.307^{* *}$ & 1.360 \\
\hline learn & & & $-.072 * *$ & .931 \\
\hline$L R R^{2}$ & \multicolumn{2}{|c|}{.023} & \multicolumn{2}{|c|}{.032} \\
\hline $\begin{array}{c}\text { Brant Test } \\
\text { (Omnibus Test) }\end{array}$ & \multicolumn{2}{|c|}{$\chi_{4}^{2}=5.14$} & \multicolumn{2}{|c|}{$\chi_{12}^{2}=29.59 * *$} \\
\hline Model Fit & \multicolumn{2}{|c|}{$\chi^{2}{ }_{1}=992.52 * *$} & \multicolumn{2}{|c|}{$\chi_{3}^{2}=1391.45^{* *}$} \\
\hline
\end{tabular}

$* \mathrm{p}<0.05 ; * * \mathrm{p}<0.01$

Table 3: A Series ( $\mathrm{j}-1)$ of Associated Binary Logistic Regression Models for the Full PO Model, Each Split Compares $\mathrm{Y}>$ cat. j to $\mathrm{Y} \leq$ cat. $\mathrm{j}$

\begin{tabular}{|c|c|c|c|c|c|c|}
\cline { 2 - 7 } \multicolumn{1}{c|}{} & $\mathrm{Y}>0$ & $\mathrm{Y}>1$ & $\mathrm{Y}>2$ & $\mathrm{Y}>3$ & $\mathrm{Y}>4$ & $\begin{array}{c}\text { Brant Test } \\
\mathrm{p} \text { Value }\end{array}$ \\
\hline Variable & Logit (b) & Logit (b) & Logit (b) & Logit (b) & Logit (b) & \\
\hline Constant & 1.00 & -1.091 & -2.014 & -3.485 & -8.523 & \\
\hline fun & .357 & .327 & .316 & .285 & .316 & .328 \\
\hline schoolwk & .286 & .278 & .293 & .351 & .492 & $.02 *$ \\
\hline learn & -.094 & -.067 & -.081 & -.068 & .144 & .094 \\
\hline
\end{tabular}

$* \mathrm{p}<0.05 ; * * \mathrm{p}<0.01$ 


\section{GENERALIZED ORDINAL LOGISTIC REGRESSION MODELS}

Results revealed that the univariate Brant tests for the PO assumption were upheld for using computers for fun and using computers to learn on their own. Conversely, the Brant test was violated for using computers for school work.

Table 4: Brant Tests of the PO Assumption for Each Predictor and the Overall Model

\begin{tabular}{|c|c|c|}
\hline Variable & Test & $\mathrm{p}$ Value \\
\hline fun & $\chi^{2}{ }_{4}=4.62$ & .328 \\
\hline schoolwk & $\chi^{2}{ }_{4}=11.55$ & $.021^{*}$ \\
\hline learn & $\chi^{2}{ }_{4}=7.93$ & .094 \\
\hline $\begin{array}{c}\text { All } \\
\text { (Full-Model) }\end{array}$ & $\chi_{12}^{2}=29.59$ & $.003^{* *}$ \\
\hline
\end{tabular}

$* \mathrm{p}<0.05 ; * * \mathrm{p}<0.01$

Results of the Generalized Ordinal Logistic Regression Model Using Stata gologit

When the PO assumption is not satisfied, Stata gologit (Fu, 1998) relaxes the proportionality assumption by allowing the logits effects of predictor variables to vary across cutpoints, which dichotomize the underlying proficiency outcome. Similar to a series of underlying binary logistic regression models where the data were dichotomized across different categories, the effects of the predictor variables estimated by the generalized ordinal logistic regression model could vary freely.

Table 5 and Figure 1 show the results of the generalized ordinal model. The logit effects and corresponding odds ratios (OR) of all three variables were different across all five models comparing probabilities of being beyond category $j$ versus at or below that category. For example, the odds ratios for using computers for fun across five comparisons were 1.428, 1.385, $1.368,1.322$ and 1.314 , respectively. They were similar because the equal slopes assumption test was tenable for this predictor variable. After relaxing the $\mathrm{PO}$ assumption, Stata gologit estimated 12 more parameters in the generalized ordinal logistic regression model than the full PO model by Stata ologit.
Results of the Generalized Ordinal Logistic Regression Model Using gologit2

Stata gologit2 (Williams, 2006) is an extension of gologit (Fu, 1998), and can estimate various types of generalized models, including the partial proportional odds model (PPO), the PO model and the binary logistic regression model. Although Stata gologit2 allows the effects of all predictor variables to vary even when some violate the PO assumption, it can relax the $\mathrm{PO}$ assumption and put equal-slope constraints on those variables whose effects are constant across cutpoints: The model is then referred to as the PPO.

Table 6 and Figure 2 show the results of the generalized ordinal logistic regression model or the PPO model using gologit2. Because only one predictor variable, using computers for school work, violated the PO assumption, the other two variables, using computers for fun and using computers to learn on their own, were held constant in the PPO model. For example, the logit coefficients and odds ratios for using computers to learn on their own were the same across five comparisons $(\mathrm{OR}=0.913)$. The $\mathrm{OR}$ for using computer for school work were different across each cutpoint, they were: 1.331, $1.329,1.342,1.436$ and 1.906 , respectively. The PPO model estimated by Stata gologit 2 was more parsimonious than the generalized ordinal logistic regression model by gologit because the former model estimated five fewer parameters than the latter.

In terms of odds ratio, using computers for fun was positively associated with the odds of being above a particular mathematics proficiency level as opposed to being at or below that level $(\mathrm{OR}=1.372)$; however, using computers to learn on their own had a negative effect on the odds of being above a particular proficiency level $(\mathrm{OR}=0.93)$. Because the effect of using computers for school work was not invariant across five comparisons, separate interpretations were required. Using computers for school work was associated with the likelihood of being in a higher mathematics proficiency level. The effects became much stronger when mathematics proficiency level moved from low to high, further, the largest effect was identified among the final comparison (proficiency level 5 versus from 0 to 4 ). 


\section{Conclusion}

This article reviewed the proportional odds model and demonstrated the use of generalized ordinal regression models to estimate mathematics proficiency. The results of fitting the PO models and the generalized ordinal logistic regression models were interpreted. In addition, two different methods used to estimate the generalized ordinal models by Williams (2006) and $\mathrm{Fu}$ (1998) were illustrated and compared.

Compared to the PO model, the generalized ordinal logistic model provides a better solution when the proportional odds assumption is violated. The effects of the predictors which meet the $\mathrm{PO}$ assumption can be interpreted in the same way as that in the PO model. The effects of explanatory variables that violate the $\mathrm{PO}$ assumption must be interpreted separately at each comparison (i.e., being beyond a particular category versus at or below that category), and need more attention.

When the proportional odds assumption is untenable, the generalized ordinal logistic model proposed by Fu (1998) may be used for preliminary analysis. Williams' model (2006) is a more powerful extension of that of $\mathrm{Fu}$ (1998) in that it incorporated and expanded Fu's procedure. Numerous different types of generalized ordinal models can be estimated by Williams' gologit2 procedure, including the commonly used partial proportional odds model (PPO), which only relaxes the PO assumption when it is violated by one or a few predictors, but holds constant for those which have equal effects. Although not provided herein, methods of model diagnostics for ordinal logistic regression models were introduced by O’Connell and Liu (2011).

Table 5: Results of the Generalized Ordinal Logit Model Using Stata gologit

\begin{tabular}{|c|c|c|c|c|c|c|c|c|c|c|}
\hline \multirow[b]{2}{*}{ Variable } & \multicolumn{2}{|c|}{$\mathrm{Y}>0$ vs. $\mathrm{Y} \leq 0$} & \multicolumn{2}{|c|}{$Y>1$ vs. $Y \leq 1$} & \multicolumn{2}{|c|}{$Y>2$ vs. $Y \leq 2$} & \multicolumn{2}{|c|}{$Y>3$ vs. $Y \leq 3$} & \multicolumn{2}{|c|}{$\mathrm{Y}>4$ vs. $\mathrm{Y} \leq 4$} \\
\hline & $\begin{array}{c}\mathrm{b} \\
(\mathrm{se}(\mathrm{b}))\end{array}$ & OR & $\begin{array}{c}\mathrm{b} \\
(\operatorname{se}(b))\end{array}$ & OR & $\begin{array}{c}\mathrm{b} \\
(\mathrm{se}(\mathrm{b}))\end{array}$ & OR & $\begin{array}{c}\mathrm{b} \\
(\mathrm{se}(\mathrm{b}))\end{array}$ & OR & $\begin{array}{c}\mathrm{b} \\
(\mathrm{se}(\mathrm{b}))\end{array}$ & OR \\
\hline fun & $\begin{array}{c}.356 \\
(.030)^{* *}\end{array}$ & 1.428 & $\begin{array}{c}.326 \\
(.016)^{* *}\end{array}$ & 1.385 & $\begin{array}{c}.313 \\
(.016)^{* *}\end{array}$ & 1.368 & $\begin{array}{c}.279 \\
(.022)^{* *}\end{array}$ & 1.322 & $\begin{array}{c}.273 \\
(.129)^{*}\end{array}$ & 1.314 \\
\hline schoolwk & $\begin{array}{c}.276 \\
(.037)^{* *}\end{array}$ & 1.318 & $\begin{array}{c}.277 \\
(.019)^{* *}\end{array}$ & 1.319 & $\begin{array}{c}.299 \\
(.018)^{* *}\end{array}$ & 1.348 & $\begin{array}{c}.370 \\
(.023)^{* *}\end{array}$ & 1.447 & $\begin{array}{c}.540 \\
(.116)^{* *}\end{array}$ & 1.716 \\
\hline \multirow[t]{2}{*}{ learn } & $\begin{array}{c}-.091 \\
(.035)^{* *}\end{array}$ & .913 & $\begin{array}{c}-.067 \\
(.017)^{* *}\end{array}$ & .935 & $\begin{array}{c}-.081 \\
(.016)^{* *}\end{array}$ & .922 & $\begin{array}{c}-.066 \\
(.019)^{* *}\end{array}$ & .936 & $\begin{array}{l}.180 \\
(.093)\end{array}$ & 1.197 \\
\hline & \multicolumn{2}{|c|}{$\alpha_{1}=1.022$} & \multicolumn{2}{|c|}{$\alpha_{2}=-1.083$} & \multicolumn{2}{|c|}{$\alpha_{3}=-2.024$} & \multicolumn{2}{|c|}{$\alpha_{4}=-3.520$} & \multicolumn{2}{|c|}{$\alpha_{5}=-8.642$} \\
\hline$L R R^{2}$ & \multicolumn{10}{|l|}{0.033} \\
\hline $\begin{array}{l}\text { Model } \\
\text { Fit }\end{array}$ & \multicolumn{10}{|c|}{$\chi_{15}^{2}=1429.62$} \\
\hline
\end{tabular}

$* \mathrm{p}<0.05 ; *{ }^{*} \mathrm{p}<0.01$ 


\section{GENERALIZED ORDINAL LOGISTIC REGRESSION MODELS}

Figure 1: Generalized Ordinal Logistic Model Using Stata gologit

gologit Profmath BYS45A_REC BYS45B_REC BYS45C_REC

Iteration 0: Log Likelihood $=-21943.368$

Iteration 1: Log Likelihood $=-21237.489$

Iteration 2: Log Likelihood $=-21228.561$

Iteration 3: Log Likelihood $=-21228.555$

Iteration 4: Log Likelihood $=-21228.555$

Generalized Ordered Logit Estimates

Number of obs $=14207$

Model $\operatorname{chi2}(15)=1429.62$

Log Likelihood $=-21228.5552037$

Prob > chi2 $=0.0000$

Pseudo R2 $=0.0326$

\begin{tabular}{|c|c|c|c|c|c|c|}
\hline Profmath | & Coef. & Std. Err. & $\mathrm{z}$ & $\mathrm{P}>|\mathrm{z}|$ & [95\% Conf. & Interval] \\
\hline \multicolumn{7}{|c|}{ 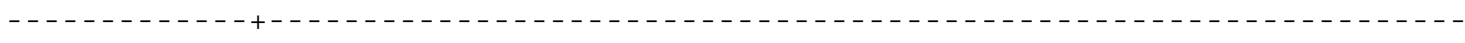 } \\
\hline \multicolumn{7}{|l|}{ mleq1 } \\
\hline BYS45A_REC | & .356211 & .0303759 & 11.73 & 0.000 & .2966753 & .4157468 \\
\hline BYS45B_REC | & .2763788 & .0372811 & 7.41 & 0.000 & .2033091 & .3494484 \\
\hline BYS45C_REC | & -.0914208 & .0350232 & -2.61 & 0.009 & -.1600651 & -.0227765 \\
\hline _cons | & 1.021761 & .1098978 & 9.30 & 0.000 & .8063653 & 1.237157 \\
\hline & -- & - & -2 & --- & $-\cdots-$ & --------- \\
\hline \multicolumn{7}{|l|}{ mleq2 } \\
\hline BYS45A_REC | & .3257729 & .01639 & 19.88 & 0.000 & .2936492 & .3578967 \\
\hline BYS45B_REC | & .2768884 & .0189779 & 14.59 & 0.000 & .2396925 & .3140843 \\
\hline BYS45C_REC | & -.0673821 & .0171035 & -3.94 & 0.000 & -.1009042 & -.0338599 \\
\hline _cons | & -1.082717 & .0676152 & -16.01 & 0.000 & -1.21524 & -.9501931 \\
\hline------- & ------- & ------ & _ & -- & ------ & - - - - - - - - \\
\hline \multicolumn{7}{|l|}{ mleq3 } \\
\hline BYS45A_REC & .3134542 & .0163592 & 19.16 & 0.000 & .2813907 & .3455177 \\
\hline BYS45B_REC | & .2989051 & .0178569 & 16.74 & 0.000 & .2639063 & .333904 \\
\hline BYS45C_REC | & -.081139 & .0155428 & -5.22 & 0.000 & -.1116022 & -.0506758 \\
\hline _cons | & -2.02405 & .0716248 & -28.26 & 0.000 & -2.164432 & -1.883668 \\
\hline----- & --- & ------- & --- & ----- & -------- & --------- \\
\hline \multicolumn{7}{|l|}{ mleq4 } \\
\hline BYS45A_REC & .2787754 & .0223384 & 12.48 & 0.000 & .234993 & .3225578 \\
\hline BYS45B_REC & .3697106 & .0227828 & 16.23 & 0.000 & .3250571 & .4143642 \\
\hline BYS 45C_REC & -.0657926 & .018757 & -3.51 & 0.000 & -.1025556 & -.0290296 \\
\hline _cons | & -3.530265 & .1037457 & -34.03 & 0.000 & -3.733603 & -3.326927 \\
\hline---------+ & --------- & -------- & ---- & ----- & -------- & ---------- \\
\hline \multicolumn{7}{|l|}{ mleq5 } \\
\hline BYS45A_REC & .27337 & .1291764 & 2.12 & 0.034 & .0201889 & .5265512 \\
\hline BYS45B_REC & .5401159 & .1155738 & 4.67 & 0.000 & .3135954 & .7666363 \\
\hline BYS45C_REC & .180175 & .0928936 & 1.94 & 0.052 & -.0018932 & .3622431 \\
\hline _cons | & -8.642421 & .6316348 & -13.68 & 0.000 & -9.880403 & -7.404439 \\
\hline
\end{tabular}


Compared to SAS, fitting generalized ordinal regression models using Stata is more straightforward because Stata does not require data restructuring and the results are easier to interpret (SAS needs an interaction term between the predictor with the violated effect and ordinal categories). The latest VGAM package (v. 0.8.3) for $\mathrm{R}$ (Yee, 2010, 2011) includes the functions of fitting the nonproportional odds and the partial proportional odds models, which is similar to Stata gologit and gologit2. Although different statistical packages may have advantages of fitting these models, the choice is left to researchers; this study does not imply an overall preference of one over another.

In educational research, the use of ordinal categorical data is common, thus, it is crucial for researchers to determine the most appropriate models to analyze ordinal categorical dependent variables. It is hoped that this demonstration clarifies some of the issues that researchers must consider in selecting appropriate statistical models for analyzing ordinal data when the PO assumption is violated.

\section{Notes}

Previous versions of this article were presented at the Modern Modeling Methods Conference in Storrs, CT (May, 2011), the $76^{\text {th }}$ Annual and the $17^{\text {th }}$ International Meeting of Psychometric Society (IMPS) in Hong Kong (July, 2011), the Northeastern Educational Research Association Annual Conference in Rocky Hill, CT (October, 2011), and the Annual Meeting of American Educational Research Association (AERA), Vancouver, British Columbia, Canada (April, 2012).

Table 6: Results of the Generalized Ordinal Logit Model/Partial Proportional Odds Model Using Stata gologit $2(\mathrm{Y}>$ cat. $\mathrm{j}$ vs. $\mathrm{Y} \leq$ cat. $\mathrm{j})$

\begin{tabular}{|c|c|c|c|c|c|c|c|c|c|c|}
\hline & \multicolumn{2}{|c|}{$\mathrm{Y}>0$ vs. $\mathrm{Y} \leq 0$} & \multicolumn{2}{|c|}{$Y>1$ vs. $Y \leq 1$} & \multicolumn{2}{|c|}{$Y>2$ vs. $Y \leq 2$} & \multicolumn{2}{|c|}{$\mathrm{Y}>3$ vs. $\mathrm{Y} \leq 3$} & \multicolumn{2}{|c|}{$\mathrm{Y}>4$ vs. $\mathrm{Y} \leq 4$} \\
\hline Variable & $\begin{array}{c}\mathrm{b} \\
(\mathrm{se}(\mathrm{b}))\end{array}$ & OR & $\begin{array}{c}\mathrm{b} \\
(\mathrm{se}(\mathrm{b}))\end{array}$ & OR & $\begin{array}{c}\mathrm{b} \\
(\mathrm{se}(\mathrm{b}))\end{array}$ & OR & $\begin{array}{c}\mathrm{b} \\
(\mathrm{se}(\mathrm{b}))\end{array}$ & OR & $\begin{array}{c}\mathrm{b} \\
(\mathrm{se}(\mathrm{b}))\end{array}$ & OR \\
\hline fun & $\begin{array}{c}.317 \\
(.014)^{* *}\end{array}$ & 1.373 & $\begin{array}{c}.317 \\
(.014)^{* *}\end{array}$ & 1.373 & $\begin{array}{c}.317 \\
(.014)^{* *}\end{array}$ & 1.373 & $\begin{array}{c}.317 \\
(.014)^{* *}\end{array}$ & 1.373 & $\begin{array}{c}.317 \\
(.014)^{* *}\end{array}$ & 1.373 \\
\hline schoolwk & $\begin{array}{c}.286 \\
(.032)^{* *}\end{array}$ & 1.331 & $\begin{array}{c}.284 \\
(.018)^{* *}\end{array}$ & 1.329 & $\begin{array}{c}.294 \\
(.017)^{* *}\end{array}$ & 1.342 & $\begin{array}{c}.362 \\
(.022)^{* *}\end{array}$ & 1.436 & $\begin{array}{c}.645 \\
(.116)^{* *}\end{array}$ & 1.906 \\
\hline learn & $\begin{array}{c}-.072 \\
(.014)^{* *}\end{array}$ & .931 & $\begin{array}{c}-.072 \\
(.014) * *\end{array}$ & .931 & $\begin{array}{c}-.072 \\
(.014)^{* *}\end{array}$ & .931 & $\begin{array}{c}-.072 \\
(.014)^{* *}\end{array}$ & .931 & $\begin{array}{c}-.072 \\
(.014) * *\end{array}$ & .931 \\
\hline & \multicolumn{2}{|c|}{$\alpha_{1}=1.073$} & \multicolumn{2}{|c|}{$\alpha_{2}=-1.060$} & \multicolumn{2}{|c|}{$\alpha_{3}=-2.053$} & \multicolumn{2}{|c|}{$\alpha_{4}=-3.650$} & \multicolumn{2}{|c|}{$\alpha_{5}=-8.357$} \\
\hline$L R R^{2}$ & \multicolumn{10}{|l|}{.032} \\
\hline $\begin{array}{l}\text { Model } \\
\text { Fit }\end{array}$ & \multicolumn{10}{|c|}{$\chi_{7}^{2}=1414.05$} \\
\hline
\end{tabular}

$* \mathrm{p}<0.05 ; * * \mathrm{p}<0.01$ 


\section{GENERALIZED ORDINAL LOGISTIC REGRESSION MODELS}

Figure 2: Generalized Ordinal Logistic Model Using Stata gologit2

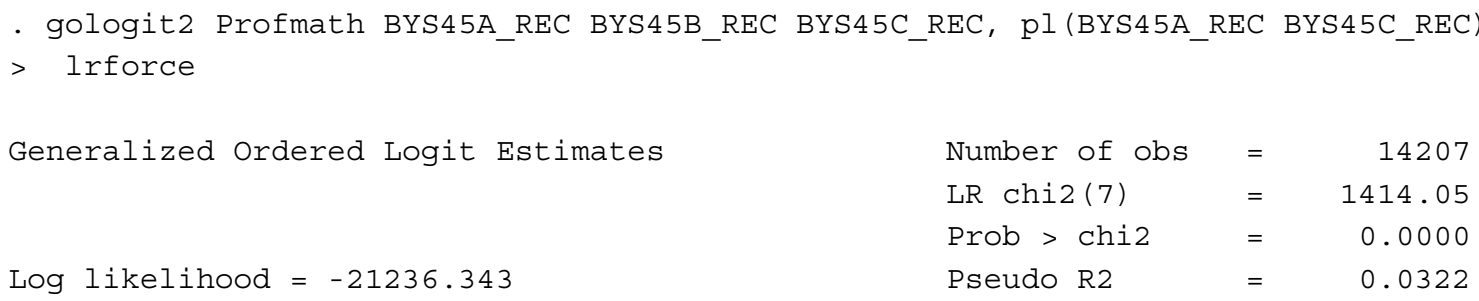

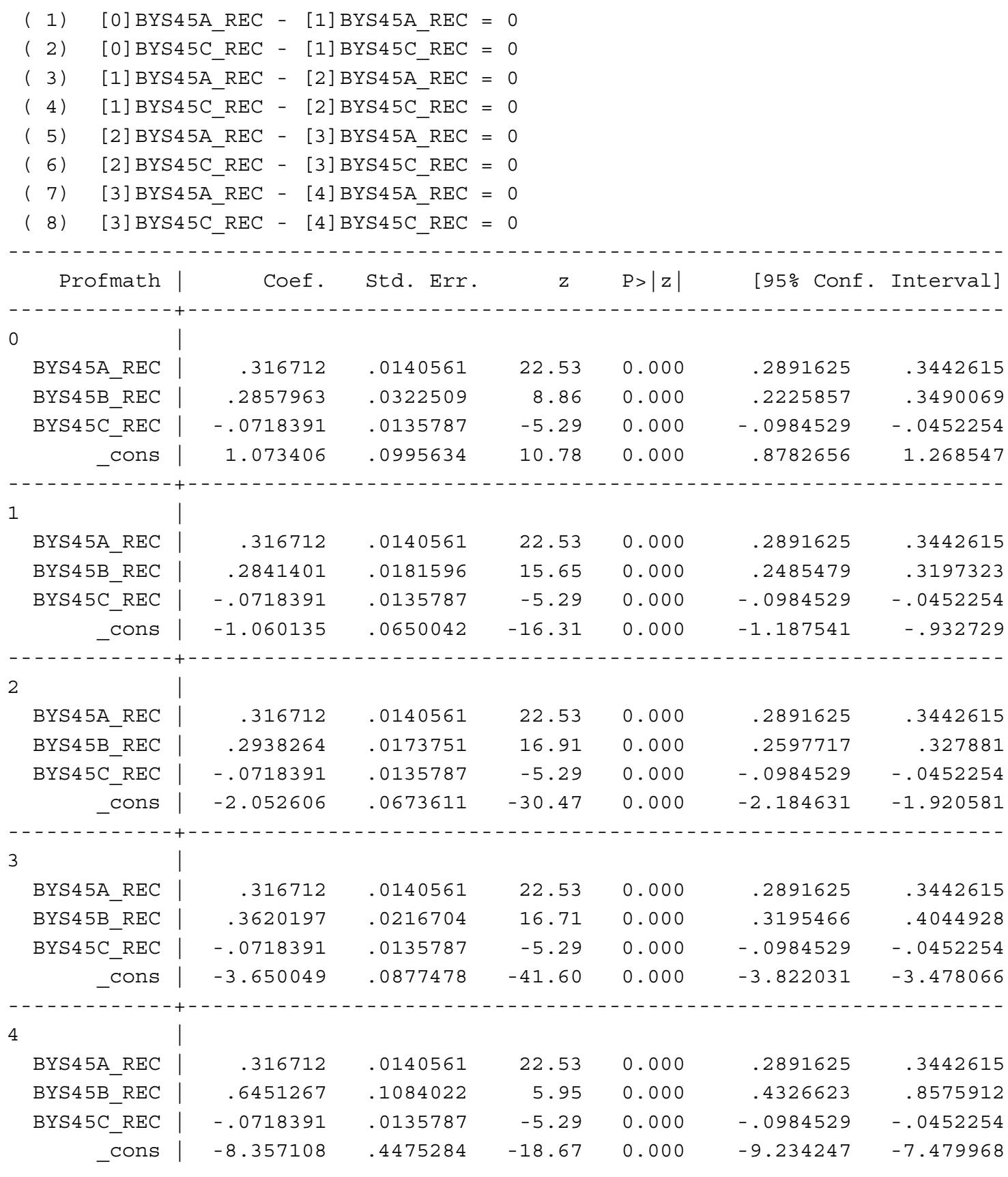




\section{XING LIU \& HARI KOIRALA}

\section{References}

Agresti, A. (1996). An introduction to categorical data analysis. New York, NY: John Wiley \& Sons.

Agresti, A. (2002). Categorical data analysis, $2^{\text {nd }} E d$. New York, NY: John Wiley \& Sons.

Agresti, A. (2007). An introduction to categorical data analysis, $2^{\text {nd }} E d$. New York, NY: John Wiley \& Sons.

Allison, P. D. (1999). Logistic regression using the SAS system: Theory and application. Cary, NC: SAS Institute, Inc.

Ananth, C. V., \& Kleinbaum, D. G. (1997). Regression models for ordinal responses: A review of methods and applications. International Journal of Epidemiology, 26, 1323-1333.

Armstrong, B. B., \& Sloan, M. (1989). Ordinal regression models for epidemiological data. American Journal of Epidemiology, 129(1), 191-204.

Bender, R., \& Benner, A. (2000). Calculating ordinal regression models in SAS and S-Plus. Biometrical Journal, 42(6), 677699.

Bender, R., \& Grouven, U. (1998). Using binary logistic regression models for ordinal data with non-proportional odds. Journal of Clinical Epidemiology, 51(10), 809-816.

Brant, R. (1990). Assessing proportionality in the proportional odds model for ordinal logistic regression. Biometrics, 46, 1171-1178.

Clogg, C. C., \& Shihadeh, E. S. (1994). Statistical models for ordinal variables. Thousand Oaks, CA: Sage.

Fienberg, S. E. (1980). The analysis of cross-classified categorical data. Cambridge, MA: The MIT Press.

$\mathrm{Fu}$, V. (1998). Estimating generalized ordered logit models. Stata Technical Bulletin, 44, 27-30.

Hardin, J. W., \& Hilbe, J. M. (2007). Generalized linear models and extensions, $2^{\text {nd }}$ $E d$. Texas: Stata Press.

Hosmer, D. W., \& Lemeshow, S. (2000). Applied logistic regression, $2^{\text {nd }} E d$. New York, NY: John Wiley \& Sons.
Ingels, S. J., Pratt, D. J., Roger, J., Siegel, P. H., \& Stutts, E. (2004). ELS: 2002 base year data file user's manual. Washington, DC: NCES (NCES 2004-405).

Ingels, S. J., Pratt, D. J., Roger, J., Siegel, P. H., \& Stutts, E. (2005). Education longitudinal study: 2002/04 public use base-year to first follow-up data files and electronic codebook system. Washington DC: NCES (NCES 2006-346).

Liu, X. (2009). Ordinal regression analysis: Fitting the proportional odds model using Stata, SAS and SPSS. Journal of Modern Applied Statistical Methods, 8(2), 632-645.

Liu, X., O'Connell, A. A., \& Koirala, H. (2011). Ordinal regression analysis: Predicting mathematics proficiency using the continuation ratio model. Journal of Modern Applied Statistical Methods, 10(2), 513-527.

Long, J. S. (1997). Regression models for categorical and limited dependent variables. Thousand Oaks, CA: Sage.

Long, J. S., \& Freese, J. (2006). Regression models for categorical dependent variables using Stata, $2^{\text {nd }} E d$. Texas: Stata Press.

McCullagh, P. (1980). Regression models for ordinal data (with discussion). Journal of the Royal Statistical Society, Series B, 42, 109-142.

McCullagh, P., \& Nelder, J. A. (1989). Generalized linear models, $2^{\text {nd }} E d$. London: Chapman and Hall.

Menard, S. (1995). Applied logistic regression analysis. Thousand Oaks, CA: Sage.

O'Connell, A. A., (2000). Methods for modeling ordinal outcome variables. Measurement and Evaluation in Counseling and Development, 33(3), 170-193.

O'Connell, A. A. (2006). Logistic regression models for ordinal response variables. Thousand Oaks, CA: SAGE.

O'Connell, A. A., \& Liu, X. (2011). Model diagnostics for proportional and partial proportional odds models. Journal of Modern Applied Statistical Methods, 10(1), 139-175.

Peterson, B., \& Harrell, F. E. (1990). Partial proportional odds models for ordinal response variables. Applied Statistics, 39(2), 205-217. 


\section{GENERALIZED ORDINAL LOGISTIC REGRESSION MODELS}

Powers, D. A., \& Xie, Y. (2000). Statistical models for categorical data analysis. San Diego, CA: Academic Press.

Stokes, M. E., Davis, C. S., \& Koch, G. G. (2000). Categorical data analysis using the SAS system. Cary, NC: SAS Institute Inc.

Williams, R. (2006). Generalized ordered logit/partial proportional odds models for ordinal dependent variables. The Stata Journal, 6(1), 58-82.
Yee, T. W. (2010). The VGAM package for categorical data analysis. Journal of Statistical Software, 32(10), 1-34.

Yee, T. W. (2011). The VGAM package for $R$. Retrieved from http://www.stat.auckland.ac.nz/ yee/VGAM. 